\title{
SOLUTE SEGREGATION IN ICE OBSERVED BY AUTORADIOGRAPHY
}

\author{
By Yukiko Mizuno and Daisuke Kuroiwa \\ (Institute of Low Temperature Science, Hokkaido University, Sapporo, Japan)
}

\begin{abstract}
Segregation of chemical impurities in ice formed from very dilute solutions was observed autoradiographically, using radioactive ${ }^{22} \mathrm{NaCl}$ or $\mathrm{H}^{36} \mathrm{Cl}$ as $\beta$-ray tracers. When water containing such radioactive solutes was frozen, the segregation of solute occurred primarily along grain boundaries and partly in grains. Successive autoradiography enabled us to observe the heterogeneous distributions of segregated impurities in ice.

RÉsumé. Ségrégation de solutions dans la glace observée par autoradiographie. La ségrégation des impuretés chimiques dans la glace formée à partir de solutions très diluées fut observée par autoradiographie au moyen de ${ }^{22} \mathrm{NaCl}$ ou $\mathrm{H}^{36} \mathrm{Cl}$ radioactifs comme traceurs de rayons $\beta$. Quand l'eau contenant de telles solutions radioactives était gelée, la séparation de la solution a lieu principalement le long des limites des grains et partiellement dans les grains. Une autoradiographie successive nous met à même d'observer les distributions hétérogènes d'impuretés isolées dans la glace.

Zusammenfassung. Lösungsabsonderung in Eis beobachtet mit Autoradiographie. Die Absonderung von chemischen Verunreinigungen in Eis, gebildet aus sehr stark verdünnten Lösungen, wurde mit autoradiographischen Methoden beobachtet. wobei radioaktives ${ }^{22} \mathrm{NaCl}$ oder $\mathrm{H}^{36} \mathrm{Cl}$ als $\beta$-Strahlenquellen verwendet wurden. Beim Gefrieren von Wasser, das solche radioaktive Lösungen enthält, tritt die Lösungsabsonderung primär entlang von Korngrenzen und teilweise in den Körnern auf. Die fortlaufende selbsttätige Autoradiographie ermöglichte uns die Beobachtung der heterogenen Verteilungen der abgesonderten Verunreinigungen im Eis.
\end{abstract}

\section{INTRODUGTION}

It is generally accepted that when water containing soluble impurities freezes, the solute molecules are not incorporated within the ice crystal lattice, but are segregated primarily at crystal grain boundaries and sometimes precipitated in grains. However, the mode of segregation or precipitation of solute in the ice may depend upon the crystallization velocity, the relative orientations between grains, the chemical nature of the solute and the solute concentration in the water. If the ice is grown from comparatively concentrated solution, the process of segregation of solute may be easily observed because of the transparency of ice. When seawater is frozen at the surface of the ocean, polygranular ice is formed. In this case the individual grains of sea ice are composed of thin lamellae made up of crystallographically oriented parallel platelets of relatively pure ice, and the solute components in sea-water are segregated between these ice platelets, and at grain boundaries, in the form of brine pores. Harrison ( 1965 ) observed that when water containing some amount of $\mathrm{K}_{2} \mathrm{CrO}_{4}$ or $\mathrm{CH}_{3} \mathrm{OH}$ was frozen, the solute segregation occurred in the form of long capillary tubes or transpiration pores filled with liquid in ice. However, if ice is grown from very dilute solutions, it becomes quite difficult to observe the mode of segregation or distribution of the solute in the ice. A rough survey of the literature seems to indicate a lack of direct observation of solute segregation in ice grown from very dilute solutions. One of the possible ways to solve this problem is to use suitable radioactive materials such as ${ }^{22} \mathrm{NaCl}$ or $\mathrm{H}^{36} \mathrm{Cl}$ as effective tracers. The main purpose of this paper is to locate or visualize autoradiographically how and where the solute segregation occurs in ice grown from extremely dilute solutions.

\section{EXPERIMENTAL}

\section{Preparation of specimen and solute concentration}

As seen in Figure I (a), a shallow container was made by placing a four-cornered frame of metallic foil on a clean slide glass $(25 \mathrm{~mm} \times 75 \mathrm{~mm})$. The four skirts of the frame $\mathrm{AB}, \mathrm{BC}, \mathrm{CD}$ and DA were stuck tightly on the slide surface with adhesive tape in such a way that no water 
leaked out from the container. A small quantity of water containing the radioactive solute was poured in the container and frozen in a cold room. After complete freezing, the foil frame was removed, and an ice plate was left on the slide surface. The ice plate was thinned carefully by the use of a microtome to the desired thickness $(0.5 \mathrm{~mm}$ by $c .2 \mathrm{~mm})$, and the shaved surface was polished and smoothed with a fine clean cloth. In the dark cold room, the sensitive emulsion of a photographic plate was brought into contact with the ice surface, and the slide glass and photographic plate were bound together with weak rubber bands (see Fig. Ib). The specimen thus made was put in a polyethylene envelope which was wrapped outside with black cloth. The specimen was then stored in the cold room at a constant temperature. After several days, the photographic plate was removed carefully from the ice surface by slightly heating the plate. Special care was taken that no melting took place at the interface between ice and emulsion. The photographic plate was then developed by a highly sensitive X-ray film developer.
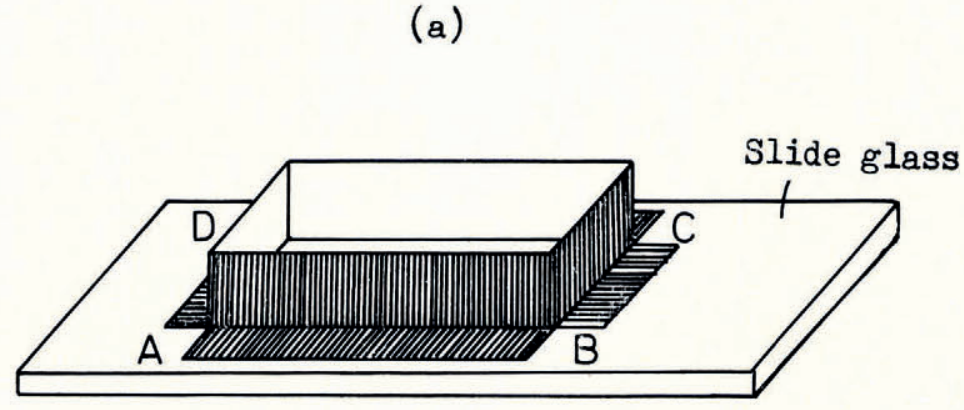

(b)

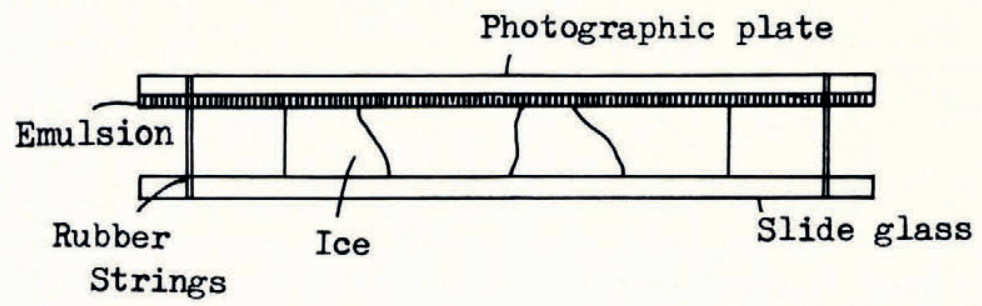

Fig. I. Schematic diagrams of the metallic foil container (a), and how the photographic plate is mounted on an ice specimen $(b)$.

The concentrations of the radioactive solute used in our experiments were $\mathrm{I} .68-3.36 \times \mathrm{IO}^{-6}$

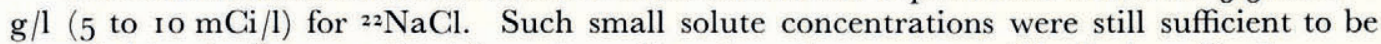
recorded by the $\beta$-rays emitted from the radioactive solute segregated in the ice. (In the cases where $\mathrm{H}^{36} \mathrm{Cl}$ was used as tracer, it was necessary to increase the concentration to 3.16 to $6.26 \times \mathrm{IO}^{-3} \mathrm{~g} / \mathrm{l}$, equivalent to $0 . \mathrm{I}$ to $0.2 \mathrm{mCi} / \mathrm{l}$, because of the longer half-life of $\left.{ }^{36} \mathrm{Cl}\right)$. The water used in the experiments was purified previously by passing it through ion exchange resin and by redistillation.

\section{Results}

Solute segregation in ice crystallized slowly

The typical autoradiograph of ${ }^{22} \mathrm{NaCl}$ segregated in ice is shown in Figure $2(\mathrm{a})$. The concentration of ${ }^{22} \mathrm{NaCl}$ was $\mathrm{I} .94 \times 1 \mathrm{I}^{-6} \mathrm{~g} / \mathrm{l}(6.6 \mathrm{mCi} / \mathrm{l})$, a value much lower than the chloride content of ordinary tap water. The ice sample which grew slowly from this dilute solution was 
transparent, but a few minute air bubbles were entrapped. The autoradiograph of this specimen was obtained at $-15^{\circ} \mathrm{C}$. As seen in this picture, the radioactive solutes segregated along grain boundaries were recorded as fine black lines (positive print). Intense segregation of the solute can be seen at the triple boundaries, the cusps of boundaries, and particular sites within grains. The size of the black spots recorded on the emulsion may be proportional to the amount of radioactive solute which emerged at the specimen surface, but the difference of the blackness of spots may depend upon the distance between the emulsion and the radioactive solute embedded in ice. If radioactive solute is directly in contact with the emulsion, it must be recorded as a thick black spot because of intense emission of $\beta$-rays, but if it is embedded deeply in ice, it may be recorded as light black spot, because the intensity of the $\beta$-rays is reduced as the result of the alsorption by ice. According to the phase diagram of ordinary
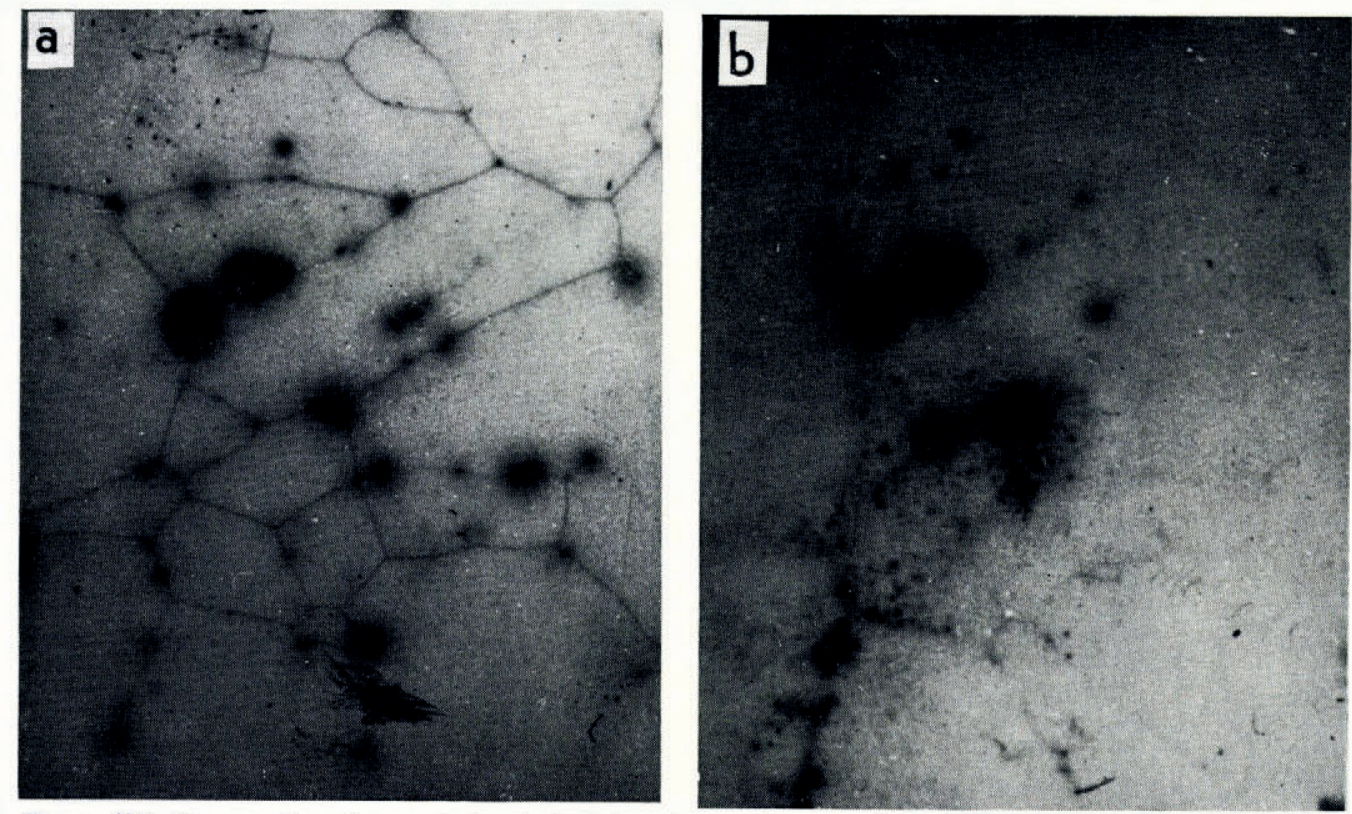

Fig. 2. ${ }^{22} \mathrm{NaCl}$ segregation along grain boundaries $(a)$, and successive autoradiography of the same specimen $(b) ; \times 7 \cdot 5$.

$\mathrm{NaCl}$ solution, the solute, $\mathrm{NaCl}$, can co-exist with ice as a liquid solution (brine) at temperatures above the eutectic point $-2 \mathrm{I} .2^{\circ} \mathrm{C}$. Therefore, in our experiments performed at $-\mathrm{I}^{\circ} \mathrm{C}$, ${ }^{22} \mathrm{NaCl}$ must be segregated in the form of a liquid film or brine inclusions in ice. The authors carefully examined grain boundaries and particular sites where the segregations of radioactive solute were recorded autoradiographically, but no discernible precipitates could be found microscopically.

After the record had been obtained, the surface layers of the specimen, approximately $30 \mu \mathrm{m}$ in thickness, were removed with a microtome. Figure 2 (b) shows the autoradiograph of this newly exposed surface. In this picture, the grain boundary segregations are somewhat blurred. However, some of the intense black spots are located in the equivalent places where intense black spots were found on Figure 2(a). These facts suggest that the solute segregated on planes and lines which extended perpendicular to the surface of the ice.

\section{Solute segregation in ice crystallized with different velocities}

The water containing ${ }^{22} \mathrm{NaCl}(6.6 \mathrm{mCi} / \mathrm{l})$ was poured in a container similar to that shown in Figure $\mathrm{I}(\mathrm{a})$ and cooled in the cold room maintained at $-5^{\circ} \mathrm{C}$. A previously cooled metal 
block was brought into contact with one side of this container. Soon, dendritic growth of ice crystals started from this side. When the dendritic crystals covered about one third of the container, the metal block was removed. Thereafter, the freezing developed slowly from the peripheries of the container towards the center. The ice sample thus obtained was fairly transparent, but many tiny air bubbles were entrapped near the center of the block. The autoradiograph taken on this specimen of ice is shown in Figure 3. Unlike the records seen in Figure 2, this record is shown by a negative print, therefore, the segregations of radioactive solute appear as white lines or spots. Careful inspection of this picture indicates that the radioactive brine inclusions were entrapped between ice lamellae formed during dendritic crystallization (left-hand side), but no segregation occurred in the region where the ice crystallized very slowly (right-hand side). The major part of the solute was segregated in the bubbly ice region near the center. This autoradiograph proves that the solute segregation in ice is primarily influenced by the crystallization velocity even when the ice is grown from such an extremely dilute solution as that used in this experiment.

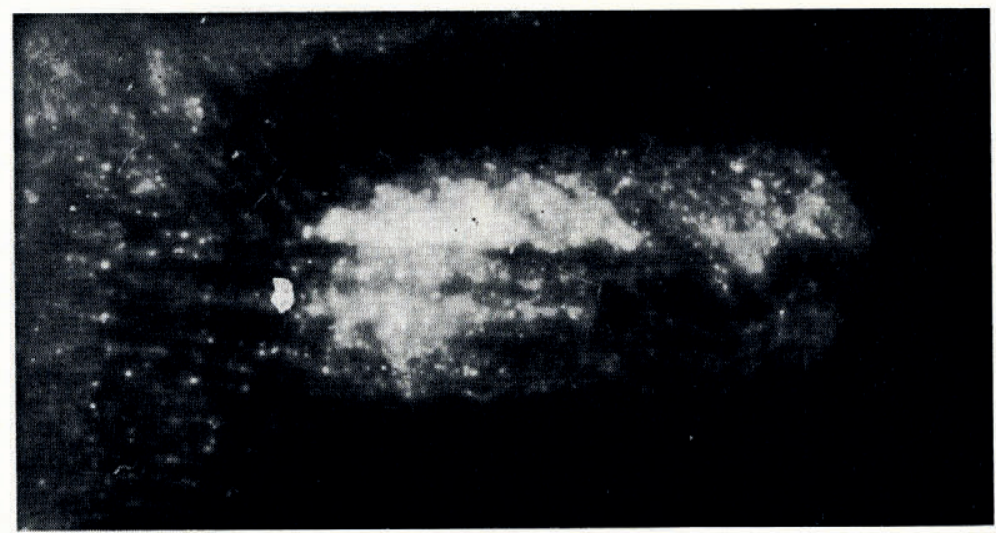

Fig. 3. ${ }^{22} \mathrm{NaCl}$ segregation in ice crystallized at different velocities; $\times 6$.

\section{Autoradiography of chemically etched ice surface}

Figure $4(\mathrm{a})$ shows the grain structure of ice crystallized from the dilute solution containing ${ }_{22} \mathrm{NaCl}\left(1.94 \times 10^{-6} \mathrm{~g} / \mathrm{l}\right)$. Figure $4(\mathrm{~b})$ is the autoradiograph of the same area of this specimen (negative print). Comparison of these two pictures shows that weak and continuous segregations occurred along grain boundaries, but comparatively intense segregation took place at triple boundaries $a$ and $b$ indicated by arrows. Several intense spots can be seen in a few grains. In spite of these intense records of the radioactive solute, no liquid precipitates or inclusions could be found microscopically at $a$ or $b$ or at any other sites in the grains. (Note that the black lines found in white spots $a$ and $b$ were produced by fine fissures of the emulsion film. These fissures were occasionally caused when the photographic plate was inadvertently removed from the specimen surface.)

After the autoradiograph shown in Figure 4(b) was taken, the surface of this specimen was etched by $\mathrm{I} \%$ Formvar solution in ethylene dichloride. The etching process was observed through a microscope. After the evaporation of solvent, a thin film of Formvar was left on the ice surface, providing the replica of the etched surface. After removing the replica film, the autoradiograph of this etched surface was obtained as shown in Figure 4 (c). As seen in this picture, the distribution of the radioactive solute is apparently different from that of Figure 4 (b). The intensity of two spots $a$ and $b$ was reduced as the result of chemical etching, and many tiny spots appeared in the region where only few spots could be seen before the etching. 

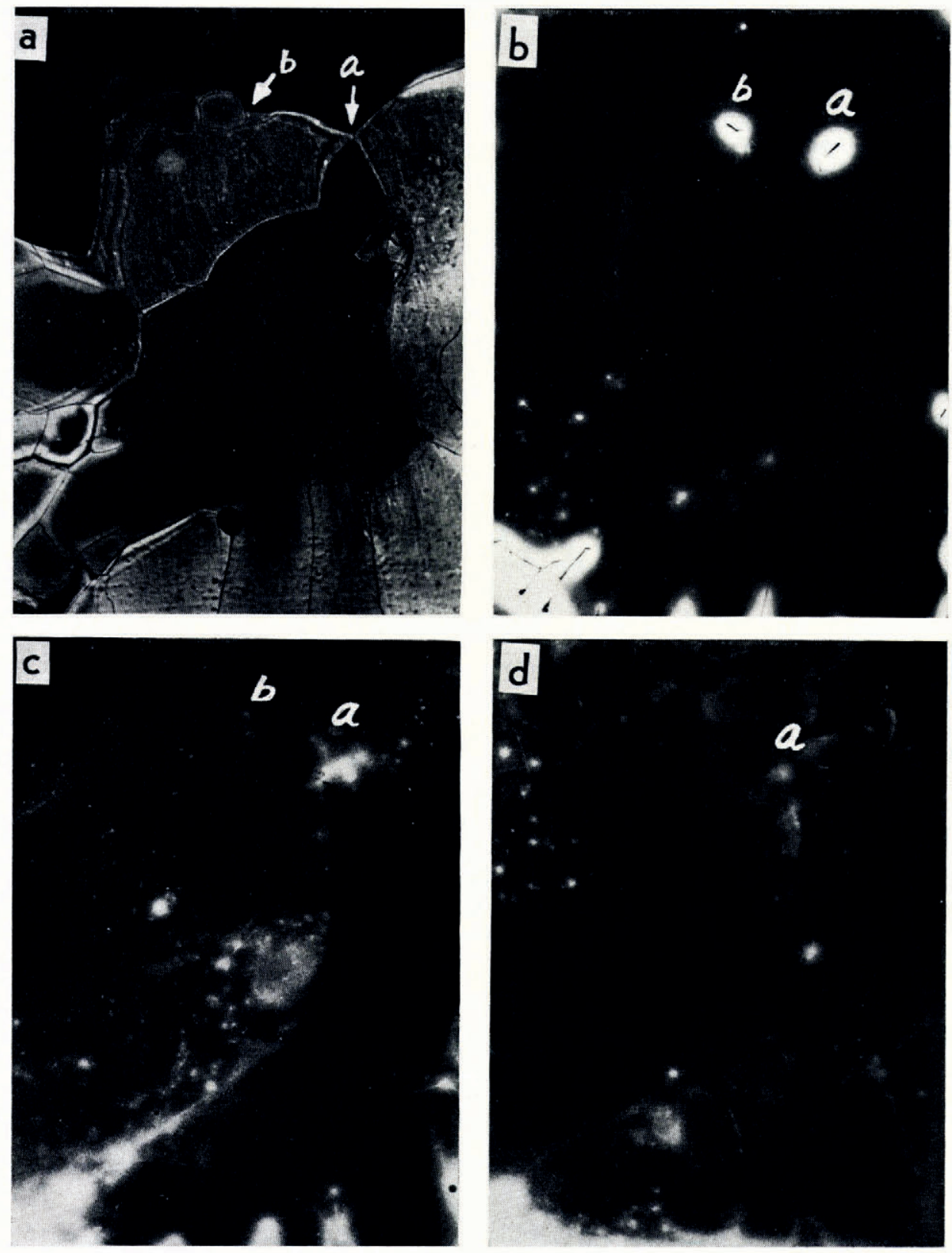

Fig. 4. Autoradiographs of a chemically etched ice surface; $\times 4$.

(a) Grain structure taken under polarized light,

(b) autoradiograph of the same specimen (before etching),

(c) autoradiograph of the same specimen (after etching),

(d) successive autoradiograph of the same specimen (after etching). 
By microscopic examination of the replica, it was found that many etch pits were created in the same region. It was difficult to check the exact correspondence between individual etch pits and newly created white spots seen in Figure 4 (c), but it may be assumed that radioactive solute inclusions embedded in the layers right underneath the surface were disclosed by the chemical etching.

In order to inquire how deeply these solute precipitates were distributed within grains, the surface of this specimen was microtomed approximately $30 \mu \mathrm{m}$ in thickness, and the new surface was etched again by the etchant. Then the autoradiograph of this surface was obtained as seen in Figure 4(d). Different patterns in the distribution of segregated solute can be seen in Figures $4(\mathrm{c})$ and (d). Many tiny white spots seen in Figure $4(\mathrm{c})$ disappeared and new spots appeared in the area where no spots could be seen in Figure $4(\mathrm{c})$, suggesting that the solute segregation within grains is not homogeneous. Note that the white spot marked by $a$ is still discernible in Figure $4(\mathrm{~d})$.

\section{Segregation of solute at sub-grain boundaries}

A specimen of ice composed of many sub-grains was formed from a very dilute solution containing $\mathrm{H}^{36} \mathrm{Cl}(0.2 \mathrm{mCi} / \mathrm{l})$. Figure 5 (a) shows the grain structure in this specimen taken in polarized light. No distinguishable difference of the crystallographic orientation was observed between these sub-grains. Figure 5 (b) shows an autoradiograph of this specimen (negative print). Though the radioactive solute was different from that used in the preceding experiments, similar segregation took place at sub-grain boundaries as well as at ordinary high-angle grain boundaries. This means that the solute segregation at grain boundaries may not be
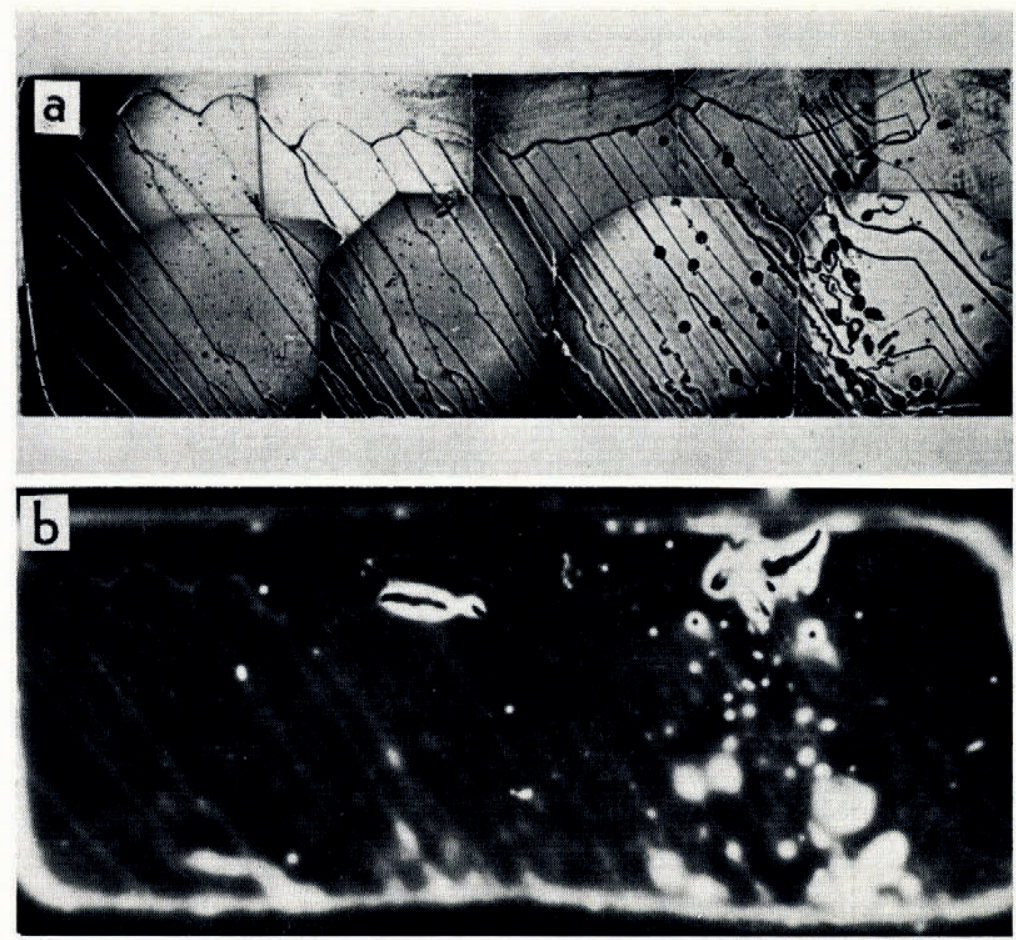

Fig. 5. Solute segregation of radioactive solute at sub-grain boundaries; $\times 4$.

(a) Grain structure taken under polarized light,

(b) autoradiograph of the same specimen $\left(\mathrm{H}^{36} \mathrm{Cl}\right.$ was used $)$. 
influenced by the relative difference in crystallographic orientation between grains, but it may be dependent upon the crystallization velocity as described above.

Note that small spherical air bubbles are entrapped in the right-hand part of this specimen (Figure 5(a)). Intense records of the radioactive solute were obtained around these individual air bubbles as shown in the autoradiograph. This means that the solute is segregated at the surface of an entrapped air bubble.

\section{Autoradiography of sublimed ice surface}

The autoradiographs described in the preceding sections were taken immediately after the specimen was prepared. Therefore, these autoradiographs gave information on the distribution patterns of segregated solute on an arbitrary cross-section through the crystals. However, if we apply autoradiography on a sublimed ice surface, it will give integrated information of the total radioactive solute segregated within the sublimed layers.

A smooth surface of polycrystalline ice containing ${ }^{22} \mathrm{NaCl}$ was exposed to the free air maintained at $-5{ }^{\circ} \mathrm{C}$ for about 2 days to allow continuous sublimation. The thickness of the sublimed layer was roughly estimated as 500-600 $\mu \mathrm{m}$. Figure 6 shows the autoradiograph of this ice surface (negative print). Many white spots and cloudy areas can be seen. These spots

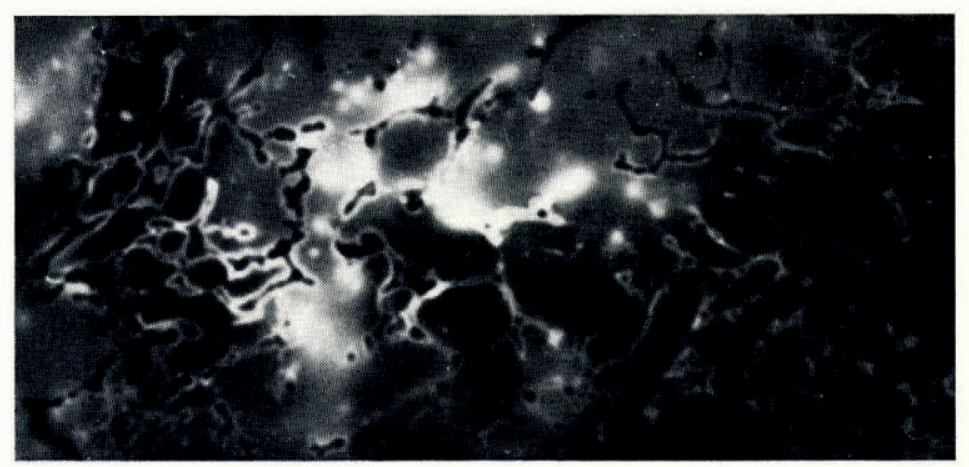

Fig. 6. Autoradiograph of a sublimed ice surface; $\times 7.5$.

and cloudy areas imply that the radioactive solute in the sublimed layer was successively precipitated on the specimen surface in the form of aggregates or dispersoids. On the other hand, the black areas seen in this picture suggest that there was no detectable solute segregation in portions of the sublimed layer. Itagaki ( 1967$)$ demonstrated that fine particles can migrate some distance on a subliming ice surface. Therefore, the precise locations of the precipitates in the sublimed layer may not be shown in this autoradiograph, but in spite of this ambiguity, it may be inferred that solute segregation does not occur uniformly in ice.

When an ice surface is exposed in air unsaturated with respect to ice, preferential sublimation occurs at grain boundaries, creating deep grooves. The reason for this is that water molecules distributed along grain boundaries are structurally weak in comparison with those sited at normal lattice sites because of distortions due to relative misfit between neighbouring grains. As soon as groove formation begins, radioactive solute particles may be gradually swept away towards both sides of the groove, forming line aggregates. As seen in this autoradiograph, deeply grooved grain boundaries were recorded as tortuous black stripes fringed with white lines. The width of black stripes must be equivalent to the width of the grooves created by sublimation, because no close contact was made between the emulsion of the photographic plate and grooves. But the line aggregates of radioactive solute make close contact with the emulsion and record white lines along both sides of grooves. 


\section{Concluding Remarks}

The segregation or precipitation of solute in ice formed from very dilute solutions was observed autoradiographically. The effective concentration of the radioactive solute, $5^{-10}$ $\mathrm{mCi} / \mathrm{l}$ for ${ }^{22} \mathrm{NaCl}$ and $0 . \mathrm{I}-0.2 \mathrm{mCi} / \mathrm{l}$ for $\mathrm{H}^{36} \mathrm{Cl}$, was adequate for obtaining a record of the $\beta$-rays within a few days. The following results were obtained: the segregation of radioactive solute occurred at the triple boundaries, at cusps on boundaries and at the surface of trapped air bubbles. The segregation of solute was also observed at particular sites within grains, but successive autoradiography showed that the distribution of segregated solute was not uniform even within the same grain. The mode of segregation depends primarily upon the crystallization velocity of ice. A quantitative analysis of the segregated solute in ice could not be obtained, but this technique allowed the identification of the exact locations or sites where the solutes were segregated in ice.

MS. received 20 May 1969

\section{REFERENCES}

Harrison, J. D. 1965. Solute transpiration pores in ice. Journal of Applied Physics, Vol. 36, No. 1, p. 326-27. [Letter.]

Itagaki, K. 1967. Particle migration on ice surfaces. (In Ōura, H., ed. Physics of snow and ice: international conference on low temperature science. ... 1966. ... Proceedings, Vol. I, Pt. 1. [Sapporo], Institute of Low Temperature Science, Hokkaido University, p. 233-46.) 